\title{
Identification of TLR2 and TLR4-induced microRNAs in human mesenchymal stem cells and their possible roles in regulating TLR signals
}

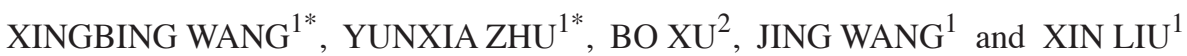 \\ ${ }^{1}$ Department of Hematology; ${ }^{2}$ Reproductive Medicine Center, Anhui Provincial Hospital, \\ Anhui Medical University, Hefei, Anhui 230001, P.R. China
}

Received March 11, 2015; Accepted January 14, 2016

DOI: $10.3892 / \mathrm{mmr} .2016 .5197$

\begin{abstract}
Toll-like receptors (TLRs) are expressed in human bone marrow-derived mesenchymal stromal cells (BM-MSCs), and the activation of TLRs is important in proliferation, differentiation, migration and hematopoiesis-supporting functions of BM-MSCs. However, the molecular mechanisms underlying these processes remain to be elucidated. MicroRNAs (miRNAs) are involved in various biological functions by mediating mRNA degradation or inhibiting translation of target genes. The present study aimed to identify whether TLRs regulate the expression of miRNAs in BM-MSCs and elucidate the regulatory roles of miRNAs. Illumina high-throughput sequencing was used to profile miRNAs expressed in BM-MSCs stimulated with TLR2 agonist, PAM ${ }_{3}$ CSK4 (PM) or TLR4 agonist, lipopolysaccharides (LPS). A marked expression change upon PM or LPS treatment was observed for 164 known miRNAs and six novel miRNAs that were identified. The expression of six novel miRNAs and 40 randomly selected known miRNAs was further validated by reverse transcription-quantitative polymerase chain reaction. In addition, bioinformatic methods were used to predict the potential target genes of the abundant known miRNAs. The gene ontology analysis demonstrated that predicted targets were enriched in the regulation of signal transduction, cellular processes and macromolecule meta-
\end{abstract}

Correspondence to: Dr Xingbing Wang, Department of Hematology, Anhui Provincial Hospital, Anhui Medical University, 17 Lujiang Road, Hefei, Anhui 230001, P.R. China

E-mail: wangxingbing91@hotmail.com

*Contributed equally

Abbreviations: BM-MSCs, bone marrow-derived mesenchymal stromal cells; GO, gene ontology; LPS, lipopolysaccharides; MAPKs, mitogen-activated protein kinases; miRNAs, microRNAs; NF- $\kappa \mathrm{B}$, nuclear factor- $\mathrm{kB}$; RT-qPCR, reverse transcription-quantitative polymerase chain reaction; TLRs, toll-like receptors

Key words: toll-like receptors, mesenchymal stem cells, microRNAs, human bolic processes. Kyoto Encyclopedia of Genes and Genomes pathway analysis suggested that these potential targets were involved in numerous important pathways, predominantly including mitogen-activated protein kinase, phosphatidylinositol-4,5-bisphosphate 3-kinase-Akt, neurotrophin and cancer-associated signaling pathways. The present study aimed to identify the global expression change of miRNAs in BM-MSCs stimulated with LPS and PM, providing the opportunity to further elucidate the roles of miRNAs in mediating TLR signals to regulate the functions of BM-MSCs.

\section{Introduction}

MicroRNAs (miRNAs) are a class of small non-coding RNAs (length, $22 \mathrm{nt}$ ) that regulate gene expression at the post-transcriptional levels. miRNAs are involved in the regulation of the majority of important biological events, including differentiation, growth, proliferation, survival, signal transduction and immune response (1-3). However, the roles of miRNAs in regulating the activation of human bone marrow-derived mesenchymal stromal cells (BM-MSCs) remain to be elucidated.

The BM-MSCs are multipotent cells that differentiate into osteoblasts, adipocytes, chondrocytes and other tissue cells (4-7). It has been demonstrated that toll-like receptors (TLRs) are expressed in MSCs to modulate their proliferation, cytokine secretion, differentiation, hematopoiesis-supporting functions and immunosuppressive capacity (8-10). Notably, it is well established that TLRs induce multiple miRNAs, which regulate TLR-signaling responses at multiple levels. For example, TLR2 and TLR4 are repressed by expression of miR-105, miR-146 and the let-7 miRNA family (11-14). However, miR-155 and miR-146b directly target numerous TLR signaling proteins $(15,16)$. Regulatory molecules, TLR-induced transcription factors and the inflammatory cytokines are also regulated by miRNAs, including miR-155 (17).

It has previously been verified that pre-stimulation with the TLR2 agonist, PAM ${ }_{3}$ CSK4 (PM) or the TLR4 agonist, lipopolysaccharides (LPS) enables BM-MSCs to enhance $\mathrm{CD} 4^{+}$cell proliferation and differentiation towards the myeloid lineage (10). To further elucidate the roles of miRNAs in mediating TLR-induced BM-MSC activation, the present 
study aimed to determine the miRNA expression profiles in unstimulated BM-MSCs and PM/LPS-stimulated BM-MSCs, using high-throughput Illumine HiSeq 2000 technology. Bioinformatic methods were also used to predict the potential target genes of the abundant known miRNAs. Furthermore, data from the present study indicated that miRNAs are involved in various important functions in human BM-MSCs, including the TLR signaling pathway.

\section{Materials and methods}

Isolation and culture of BM-MSCs. BM-MSCs were isolated from fresh bone marrow by sterile puncture of a healthy donor. The present study was approved by the Anhui Medical University Ethics Committee, and informed written consent was obtained from the donor. The isolation, expansion and identification of BM-MSCs were performed as described previously (10). Briefly, following density gradient centrifugation over Ficoll-Hypaque (1.077 g/ml; Beijing Solarbio Science \&Technology Co., Ltd., Beijing, China), BM-MSCs were cultured $\left(1 \times 10^{6}\right.$ cells $\left./ \mathrm{ml}\right)$ in Dulbecco's High Glucose Modified Eagles Medium (GE Healthcare Life Sciences, Logan, UT, USA), supplemented with $10 \%$ fetal calf serum (Gibco; Thermo Fisher Scientific, Inc., Waltham, MA, USA) and containing $5 \% \mathrm{CO}_{2}$ at $37^{\circ} \mathrm{C}$. Non-adherent cells were removed after $24 \mathrm{~h}$ and the culture medium was changed twice a week. Adherent cells were cultured until 80-90\% confluence was reached, after which trypsin ( $0.25 \%$; Gibco) digestion was conducted on passage three cells. BM-MSCs were analyzed by flow cytometry (FACSCalibur ${ }^{\mathrm{TM}}$; BD Biosciences, Franklin Lakes, NJ, USA) following staining with monoclonal antibodies, as follows: Fluorescein isothiocyanate (FITC)-conjugated anti-cluster of differentiation (CD) 90 (1:10; cat. no. 555595); FITC-anti-CD14 (1:10; cat. no. 555397), phycoerythrin (PE)-anti-CD29 (cat. no. 555443), cyanine5-PE-anti-CD34 (cat. no. 555823), PE-anti-CD166 (cat. no. 559263), FITC-anti-CD44 (1:10; cat. no. 555478), PE-anti-CD31 (1:10; cat. no. 560983), FITC-anti-CD45 (1:10; cat. no. 555482), PE-anti-CD13 (1:10; cat. no. 560998) and FITC-anti-CD105 (1:10; cat. no. 561443; all: BD Biosciences). BM-MSCs were confirmed by negative staining of hematopoietic and endothelial lineage markers (CD14, CD34, CD31 and CD45) and positive staining of CD90, CD105, CD166, CD29, CD44 and CD13.

PM and LPS stimulation. LPS (100 $\mathrm{ng} / \mathrm{ml})$ and PM (100 ng/ml) were purchased from R\&D Systems, Inc. (Minneapolis, Minnesota, USA). The BM-MSC feeder layers in 12-well plates were stimulated with (experimental group) or without (control) TLR2 agonist, PM, or TLR4 agonist, LPS, for $24 \mathrm{~h}$. The supernatants were removed and the feeder layers were washed twice with fresh culture medium.

Total RNA extraction and small RNA sequencing library preparation. Total RNA was isolated from confluent MSCs with TRIzol (Promega Corporation, Madison, WI, USA). The purity and concentration of total RNA samples were determined with NanoDrop ND-1000 (Thermo Fisher Scientific, Inc., Wilmington, DE, USA). Total RNA of each sample was used to prepare the miRNA sequencing library using the
TruSeq Small RNA Library Prep kit (RS-200-0012; Illumina, Inc., San Diego, CA, USA), according to the manufacturer's protocol. This included the following steps: i) 3'-Adapter ligation with truncated T4 RNA ligase 2 (New England BioLabs, Inc., Ipswich, MA, USA); ii) 5'-adapter ligation with T4 RNA ligase (Ambion; Thermo Fisher Scientific, Inc.); iii) cDNA synthesis with reverse transcription primers (Bioligo Biological Technology, Co., Ltd., Shanghai, China); iv) polymerase chain reaction (PCR) amplification; and v) extraction and purification of PCR amplified fragments [length, 138-158 bp; corresponding to small RNAs (length, 15-35 nt)] from the agarose gel. Subsequently, the completed libraries were quantified with an Agilent 2100 Bioanalyzer (Agilent Technologies, Inc., Santa Clara, CA, USA).

Small RNA sequencing. The samples were diluted to a final concentration of $8 \mathrm{pM}$ and cluster generation was performed on the Illumina cBot using TruSeq Rapid SR cluster kit (Illumina, Inc.), following the manufacturer's protocols. Sequencing was performed on an Illumina HiSeq 2000 using TruSeq Rapid SBS kits (Illumina, Inc.), according to the manufacturer's protocols. The DNA fragments in the libraries were denatured with $0.1 \mathrm{M} \mathrm{NaOH}$ to generate single-stranded DNA molecules, captured on flow cells (Illumina, Inc.), amplified in situ and finally sequenced for 36 cycles on Illumina HiSeq 2000.

Analysis of sequencing data and length distribution. Using high throughput sequencing with an Illumina Hiseq 2000, total clean reads from the control and trial libraries were obtained, and the length distribution of the clean reads was summarized. Image analysis and base calling were performed using Off-Line Basecaller software (v1.8.0; Illumina, San Diego, CA, USA). Subsequently, the 3'-adapter sequence was trimmed from the clean reads [that had passed the Solexa CHASTITY quality filter (Illumina)] and the reads of length $<15 \mathrm{nt}$ were discarded. Remaining reads (length, $\geq 15 \mathrm{nt}$ ) were aligned to the latest known human reference miRNA precursor set [Sanger miRBase 19 (http://www.mirbase.org/)] using Novoalign software (v2.07.11; http://www.novocraft. com/products/novoalign/). Reads ( $<2$ counts) were discarded when calculating the miRNA expression. In order to characterize the isomiR variability, any sequence that matched the miRNA precursors in the mature miRNA region \pm 4 nt (with $\leq 1$ mismatch) were accepted as mature miRNA isomiRs, which were grouped according to the 5-prime (5p) or 3-prime (3p) arm of the precursor hairpin.

Prediction of novel miRNAs. miRDeep2 (http://www. mdc-berlin.de/en/research/research_teams/systems_biology_ of_gene_regulatory_elements/projects/miRDeep) was used to predict novel miRNAs. For novel miRNA prediction, all sequence data was pooled from the following 3'-adapter trimmed files: LPS, PM and con-trimmed_tags.fa, all adapter trimmed sequences of length $<17 \mathrm{bp}$ and mismatch $>1$ were excluded from the prediction pipeline. The higher the novel miRNA score of the miRDeep2, the more reliable the novel miRNA was considered to be.

Target gene prediction. Three online search algorithms, TargetScan version 6.2 ( http://www.targetscan.org/vert_60/) 
Table I. Downregulated miRs in bone marrow-derived mesenchymal stem cells stimulated with lipopolysaccharide.

\begin{tabular}{|c|c|}
\hline miR name & Fold change \\
\hline hsa-let-7a-3p & 0.333333333 \\
\hline hsa-miR-1 & 0.157248157 \\
\hline hsa-miR-125a-5p & 0.403608737 \\
\hline hsa-miR-132-5p & 0.161290323 \\
\hline hsa-miR-137 & 0.253012048 \\
\hline hsa-miR-154-3p & 0.153846154 \\
\hline hsa-miR-15a-5p & 0.359223301 \\
\hline hsa-miR-181a-5p & 0.287637856 \\
\hline hsa-miR-181c-3p & 0.450000000 \\
\hline hsa-miR-186-5p & 0.128352490 \\
\hline hsa-miR-199a-3p & 0.309404320 \\
\hline hsa-miR-199b-3p & 0.309404320 \\
\hline hsa-miR-221-3p & 0.280632896 \\
\hline hsa-miR-222-3p & 0.374696936 \\
\hline hsa-miR-24-3p & 0.333686441 \\
\hline hsa-miR-29a-3p & 0.187765957 \\
\hline hsa-miR-30d-5p & 0.437901499 \\
\hline hsa-miR-30e-5p & 0.300376648 \\
\hline hsa-miR-323a-3p & 0.182186235 \\
\hline hsa-miR-323b-3p & 0.094527363 \\
\hline hsa-miR-335-5p & 0.413793103 \\
\hline hsa-miR-337-3p & 0.482758621 \\
\hline hsa-miR-361-5p & 0.454545455 \\
\hline hsa-miR-369-3p & 0.404193782 \\
\hline hsa-miR-374a-5p & 0.271111111 \\
\hline hsa-miR-380-3p & 0.400000000 \\
\hline hsa-miR-411-3p & 0.083179298 \\
\hline hsa-miR-425-5p & 0.016032811 \\
\hline hsa-miR-450a-5p & 0.183206107 \\
\hline hsa-miR-708-5p & 0.258064516 \\
\hline hsa-miR-941 & 0.131578947 \\
\hline hsa-miR-99b-5p & 0.476327116 \\
\hline
\end{tabular}

miR, microRNA.

and miRanda (http://www.Microrna.org/microrna/home. do) and MicroCosm Targets version 5 (http://www.ebi. ac.uk/enright-srv/microcosm/htdocs/targets/v5/) were used to predict the target genes of differentially expressed (DE) miRNAs among the BM-MSCs activated with the TLR2 and TLR4 agonists, and BM-MSCs in the absence of agonists. The annotated miRNA target genes that were selected from all the algorithms were considered to be the target genes.

Gene ontology (GO) and Kyoto Encyclopedia of Genes and Genomes (KEGG) pathway analysis of the predicted miRNA target genes. In order to further realize the functions, the predicted target genes were subjected to the analysis of GO project (http://www.geneontology.org). Fisher's exact test was used to find whether there was increased overlap between the DE list and the GO annotation list than would be expected by chance. The P-value denotes the significance of GO
TableII.UpregulatedmiRs inbonemarrow-derivedmesenchymal stem cells stimulated with lipopolysaccharide.

\begin{tabular}{lr}
\hline miR name & Fold change \\
\hline hsa-let-7b-5p & 2.918778428 \\
hsa-miR-100-5p & 10.847709700 \\
hsa-miR-106a-5p & 2.083333333 \\
hsa-miR-106b-5p & 5.405405405 \\
hsa-miR-125a-3p & 3.090909091 \\
hsa-miR-126-3p & 2.282608696 \\
hsa-miR-128 & 10.200000000 \\
hsa-miR-136-3p & 2.000000000 \\
hsa-miR-138-5p & 15.218750000 \\
hsa-miR-146a-5p & 2.125000000 \\
hsa-miR-155-5p & 19.623376620 \\
hsa-miR-17-5p & 5.828767123 \\
hsa-miR-18a-5p & 4.888888889 \\
hsa-miR-199a-5p & 32.703703700 \\
hsa-miR-20a-5p & 4.294478528 \\
hsa-miR-218-5p & 4.400000000 \\
hsa-miR-22-5p & 2.133333333 \\
hsa-miR-224-5p & 12.050000000 \\
hsa-miR-26a-5p & 8.077169132 \\
hsa-miR-26b-5p & 2.234290470 \\
hsa-miR-32-3p & 2.750000000 \\
hsa-miR-34a-5p & 2.252148997 \\
hsa-miR-3591-5p & 3.214285714 \\
hsa-miR-361-3p & 4.136363636 \\
hsa-miR-369-5p & 2.222222222 \\
hsa-miR-424-3p & 9.666666667 \\
hsa-miR-425-3p & 3.461538462 \\
hsa-miR-455-3p & 6.421052632 \\
hsa-miR-486-5p & 3.418918919 \\
hsa-miR-497-5p & 2.230769231 \\
hsa-miR-548d-5p & 2.800000000 \\
hsa-miR-574-5p & 7.65185185 \\
hsa-miR-7-5p & \\
\hline
\end{tabular}

miR, microRNA.

term enrichment in the DE genes; the lower the P-value, the more significant the GO term $(\mathrm{P}<0.05$ is recommended). Furthermore, pathway analysis was performed for these target genes. Pathway analysis is a functional analysis that maps genes to the KEGG pathways. The P-value (EASE-score, Fisher's method P-value or hypergeometric P-value) indicates the significance of the pathway correlated to the conditions. A lower $\mathrm{P}$-value, indicates a more significant pathway $(\mathrm{P}<0.05$ is recommended).

Validation of miRNA expression by quantitative PCR ( $q P C R$ ). A random selection of DE miRNAs between the experimental and control groups from the sequencing data was validated by qPCR. Corroboration of the six novel miRNAs 
Table III. Downregulated miRs in bone marrow derived mesenchymal stem cells stimulated with $\mathrm{PAM}_{3} \mathrm{CSK} 4$.

\begin{tabular}{|c|c|}
\hline miR name & Fold change \\
\hline hsa-let-7a-3p & 0.339080460 \\
\hline hsa-miR-1 & 0.090909091 \\
\hline hsa-miR-101-3p & 0.413533835 \\
\hline hsa-miR-103a-3p & 0.169556840 \\
\hline hsa-miR-106b-3p & 0.383177570 \\
\hline hsa-miR-107 & 0.200000000 \\
\hline hsa-miR-10a-5p & 0.263522618 \\
\hline hsa-miR-10a-3p & 0.406250000 \\
\hline hsa-miR-10b-5p & 0.276625387 \\
\hline hsa-miR-125b-5p & 0.449112979 \\
\hline hsa-miR-125b-1-3p & 0.409638554 \\
\hline hsa-miR-132-5p & 0.322580645 \\
\hline hsa-miR-134 & 0.266187050 \\
\hline hsa-miR-137 & 0.409638554 \\
\hline hsa-miR-140-5p & 0.369565217 \\
\hline hsa-miR-146b-5p & 0.250539957 \\
\hline hsa-miR-148a-5p & 0.385714286 \\
\hline hsa-miR-148b-5p & 0.458333333 \\
\hline hsa-miR-151a-3p & 0.343228200 \\
\hline hsa-miR-154-3p & 0.1111111110 \\
\hline hsa-miR-181c-3p & 0.316666667 \\
\hline hsa-miR-186-5p & 0.223180077 \\
\hline hsa-miR-190a & 0.284424379 \\
\hline hsa-miR-191-5p & 0.262476895 \\
\hline hsa-miR-199a-3p & 0.255945887 \\
\hline hsa-miR-199b-3p & 0.255945887 \\
\hline hsa-miR-21-3p & 0.239819005 \\
\hline hsa-miR-210 & 0.234042553 \\
\hline hsa-miR-221-3p & 0.215810131 \\
\hline hsa-miR-222-3p & 0.383072515 \\
\hline hsa-miR-27a-5p & 0.405405405 \\
\hline hsa-miR-27b-3p & 0.278292181 \\
\hline hsa-miR-29a-3p & 0.392021277 \\
\hline hsa-miR-30c-2-3p & 0.431818182 \\
\hline hsa-miR-30d-5p & 0.423982869 \\
\hline hsa-miR-30e-5p & 0.284369115 \\
\hline hsa-miR-323a-3p & 0.287449393 \\
\hline hsa-miR-323b-3p & 0.074626866 \\
\hline hsa-miR-335-3p & 0.438016529 \\
\hline hsa-miR-34c-5p & 0.138211382 \\
\hline hsa-miR-369-3p & 0.149674620 \\
\hline hsa-miR-374a-5p & 0.182222222 \\
\hline hsa-miR-379-5p & 0.346481876 \\
\hline hsa-miR-411-3p & 0.118299445 \\
\hline hsa-miR-425-5p & 0.026099925 \\
\hline hsa-miR-450a-5p & 0.114503817 \\
\hline hsa-miR-493-5p & 0.460829493 \\
\hline hsa-miR-671-5p & 0.326530612 \\
\hline hsa-miR-708-5p & 0.370967742 \\
\hline hsa-miR-92a-3p & 0.430016863 \\
\hline hsa-miR-99b-5p & 0.199426112 \\
\hline
\end{tabular}

miR, microRNA.
Table IV. Upregulated miRs in bone marrow-derived mesenchymal stem cells stimulated with $\mathrm{PAM}_{3} \mathrm{CSK} 4$.

\begin{tabular}{|c|c|}
\hline miR name & Fold change \\
\hline hsa-let-7a-5p & 4.209545028 \\
\hline hsa-let-7b-5p & 6.022742040 \\
\hline hsa-let-7c & 3.173728814 \\
\hline hsa-let-7d-5p & 11.85106383 \\
\hline hsa-let-7e-5p & 2.807106599 \\
\hline hsa-let-7f-5p & 2.787247317 \\
\hline hsa-let-7g-5p & 2.138705416 \\
\hline hsa-miR-100-5p & 9.835217133 \\
\hline hsa-miR-106b-5p & 4.783783784 \\
\hline hsa-miR-127-3p & 2.286982249 \\
\hline hsa-miR-1307-5p & 2.181818182 \\
\hline hsa-miR-130a-3p & 2.319148936 \\
\hline hsa-miR-136-3p & 2.102564103 \\
\hline hsa-miR-146a-5p & 22.854166670 \\
\hline hsa-miR-155-5p & 5.000000000 \\
\hline hsa-miR-15b-5p & 3.800000000 \\
\hline hsa-miR-17-3p & 2.000000000 \\
\hline hsa-miR-185-5p & 2.1111111110 \\
\hline hsa-miR-18a-5p & 2.222222222 \\
\hline hsa-miR-193b-3p & 4.820512821 \\
\hline hsa-miR-195-5p & 16.080000000 \\
\hline hsa-miR-196a-5p & 2.655948553 \\
\hline hsa-miR-214-3p & 84.462585030 \\
\hline hsa-miR-23a-3p & 3.709433962 \\
\hline hsa-miR-23b-3p & 5.725806452 \\
\hline hsa-miR-23c & 6.500000000 \\
\hline hsa-miR-24-3p & 29.494703390 \\
\hline hsa-miR-27b-5p & 5.000000000 \\
\hline hsa-miR-28-5p & 2.307692308 \\
\hline hsa-miR-320a & 2.166666667 \\
\hline hsa-miR-335-5p & 2.379310345 \\
\hline hsa-miR-374b-3p & 4.285714286 \\
\hline hsa-miR-376c-3p & 2.636363636 \\
\hline hsa-miR-377-3p & 2.133333333 \\
\hline hsa-miR-421 & 3.884615385 \\
\hline hsa-miR-423-5p & 2.112903226 \\
\hline hsa-miR-424-5p & 2.350000000 \\
\hline hsa-miR-431-5p & 3.600000000 \\
\hline hsa-miR-4510 & 6.818181818 \\
\hline hsa-miR-484 & 2.535714286 \\
\hline hsa-miR-487b & 3.000000000 \\
\hline hsa-miR-493-3p & 2.100000000 \\
\hline hsa-miR-598 & 2.300000000 \\
\hline hsa-miR-92b-3p & 3.000000000 \\
\hline hsa-miR-941 & 5.400000000 \\
\hline hsa-miR-99a-5p & 2.523255814 \\
\hline
\end{tabular}

miR, microRNA.

was performed according to the previously described conditions using qPCR assays. Total RNA was isolated from each 


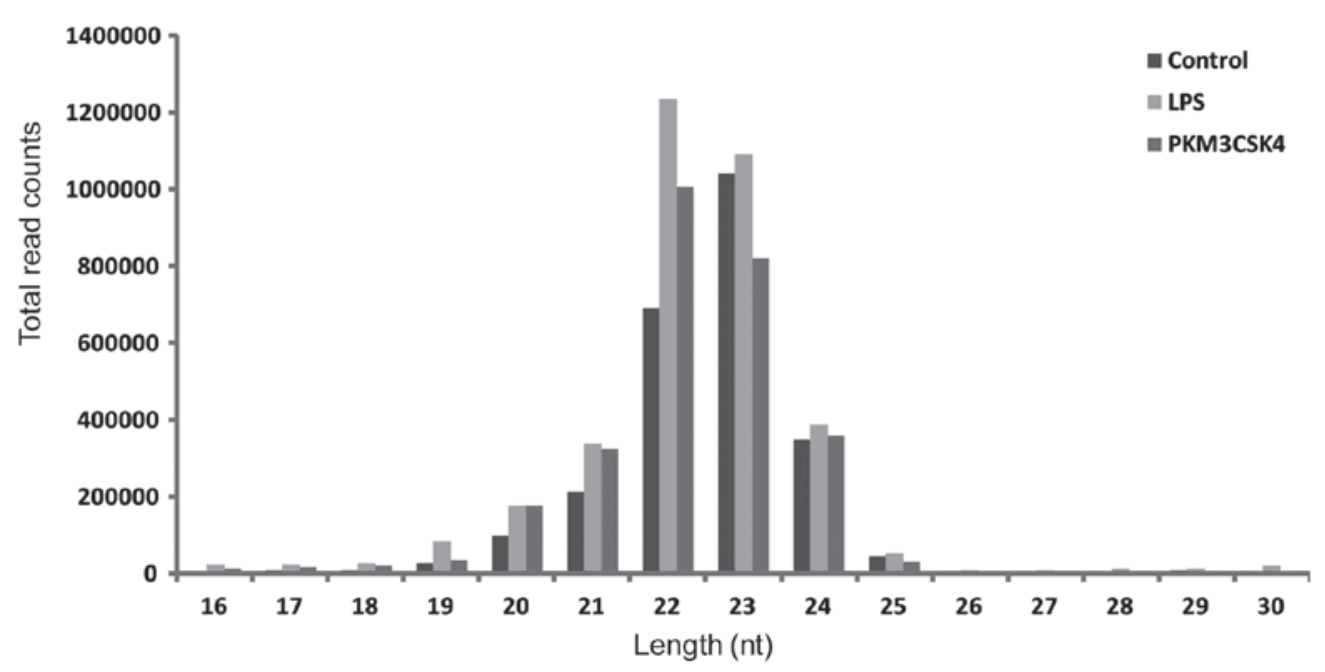

Figure 1. Length distribution of sequence total reads in control and trial libraries. LPS, lipopolysaccharides.

A

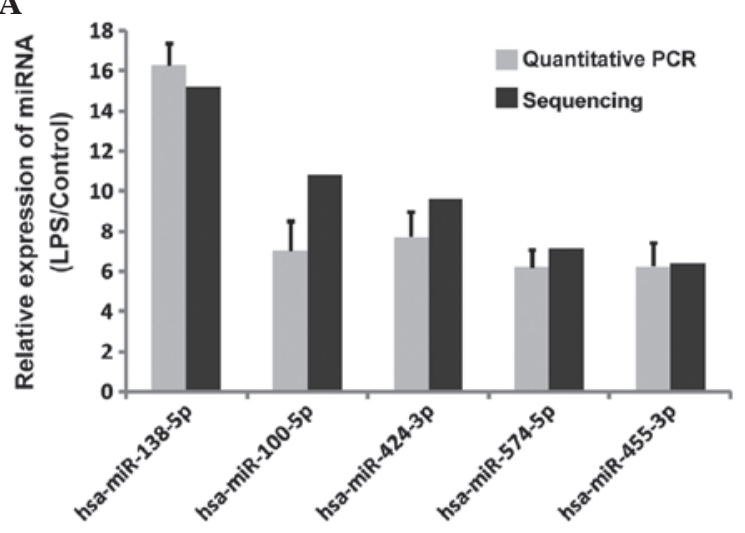

C

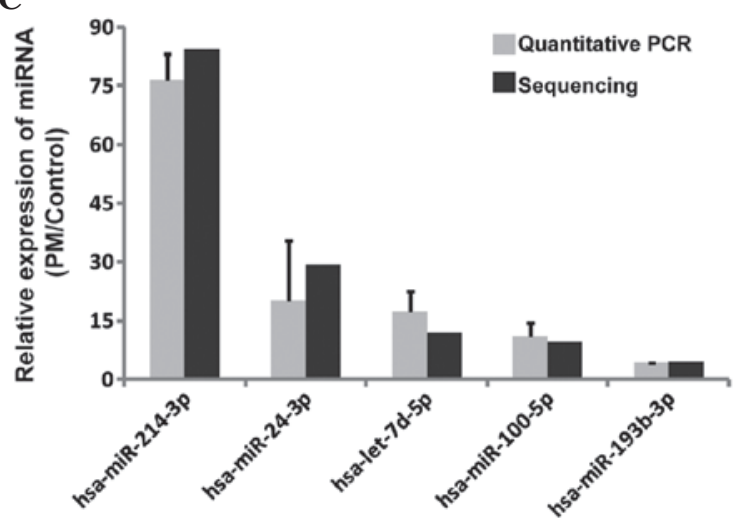

B

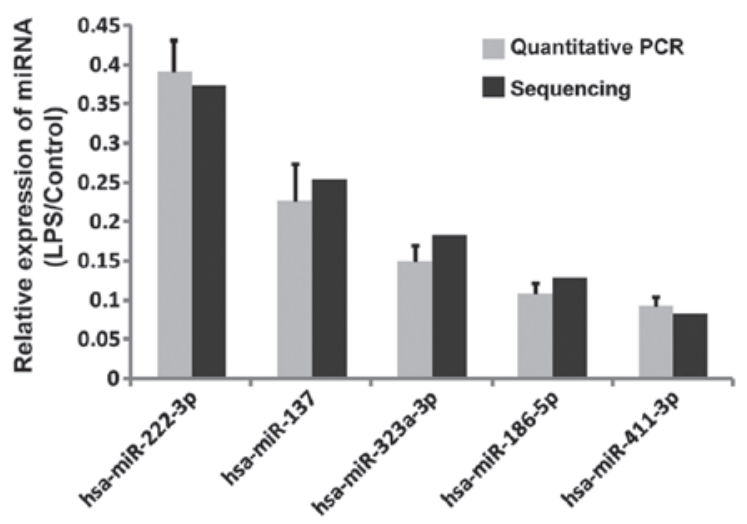

D

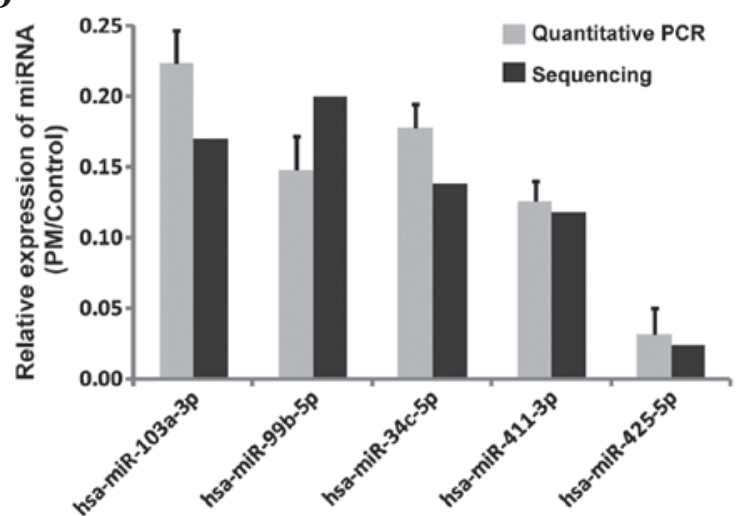

Figure 2. Confirmation of the differentially expressed miRNAs in PM or LPS stimulated bone marrow-derived mesenchymal stem cells and control groups. The expression of 10 miRNAs was validated by next-generation sequencing and quantitative PCR using differential expression patterns. The (A) increased and (B) decreased expression of miRNAs in the LPS group, and the (C) increased and (D) decreased expression miRNAs in the PM group. miRNA, microRNA; PCR, polymerase chain reaction; LPS, lipopolysaccharides; PM, PAM ${ }_{3}$ CSK4.

sample using TRIzol ${ }^{\circledR}$ reagent (Invitrogen; Thermo Fisher Scientific, Inc.). The miRNA quantification was performed by qPCR using Applied Biosystems StepOne Real-Time PCR system (Thermo Fisher Scientific, Inc.) and SYBR premix Ex Taq II kit (Takara Bio, Inc.) according to the manufacturer's protocols. U6 served to normalize the levels of all miRNA transcripts, the primer sequences were forward, 5'-GCTTCG GCAGCACATATACTAAAAT-3' and reverse, 5'-CGCTTC ACGAATTTGCGTGTCAT-3' for U6. Relative expression of miRNA was evaluated by the $2^{-\Delta \Delta C q}$ method (18). All miRNA samples and the internal reference U6 were run in a qPCR reaction. Thermal cycling conditions of the qPCR were $95^{\circ} \mathrm{C}$ 


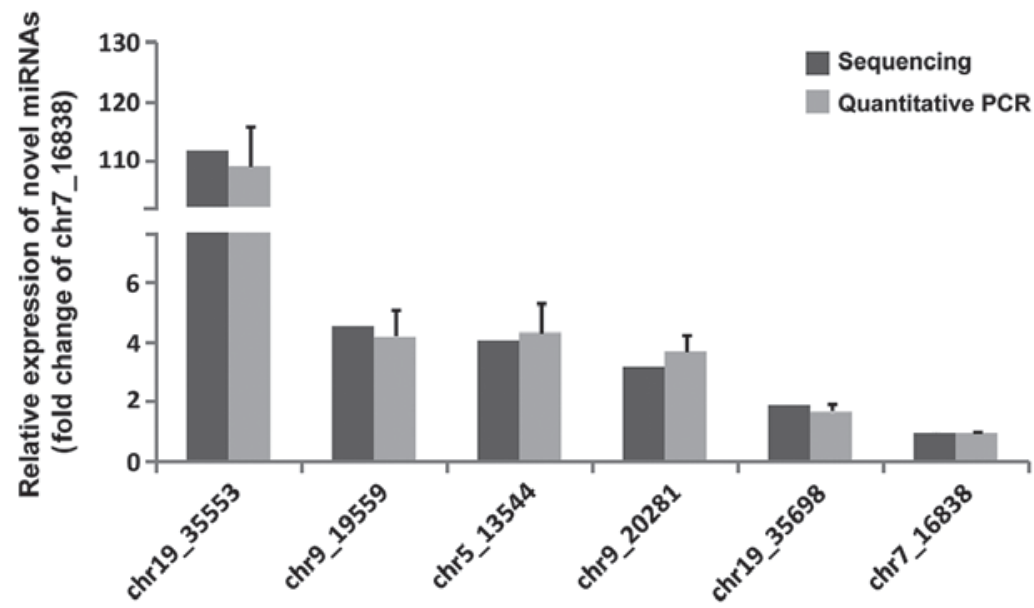

Figure 3. Confirmation of novel miRNA expression detected by next-generation sequencing. miRNA, microRNA; PCR, polymerase chain reaction.

A

$\mathbf{B}$

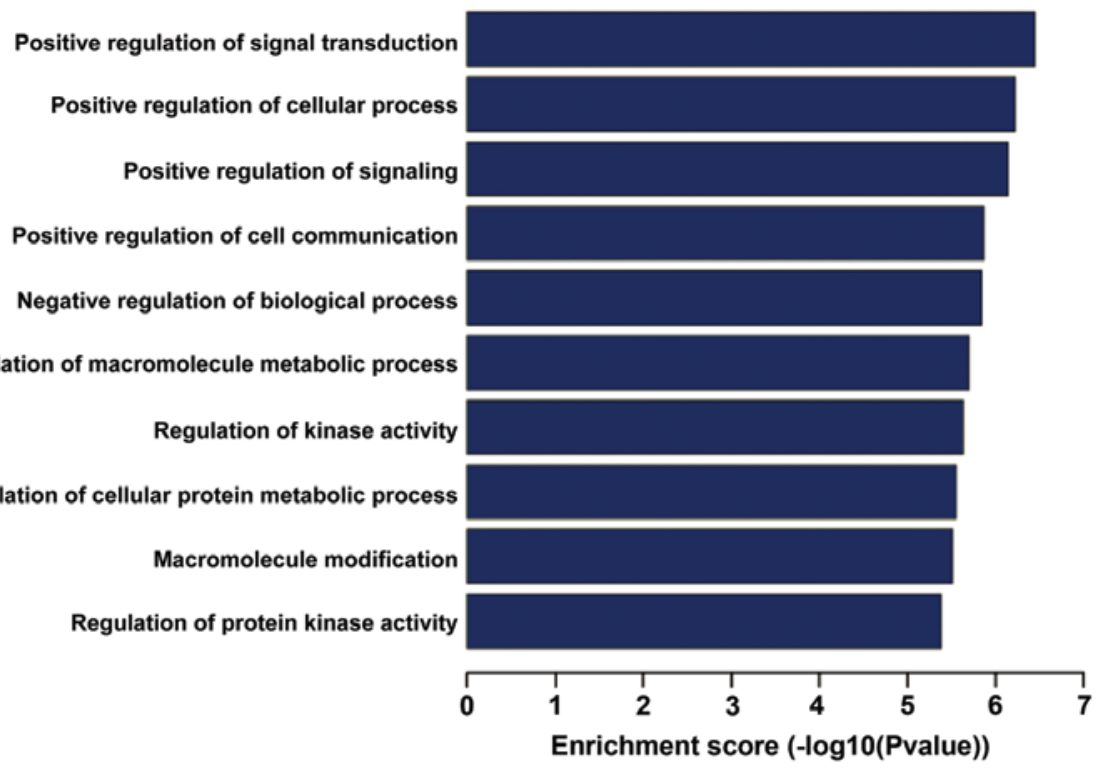

Negative regulation of biological process

System development

Transcription from RNA polymerase II promote

Regulation of transcription from RNA polymerase II promoter

Negative regulation of cellular process

Cell morphogenesis involved in differentiation

Cell differentiatio

Cell morphogenesis involved in neuron differentiation

Positive regulation of RNA metabolic proces

Axon guidance
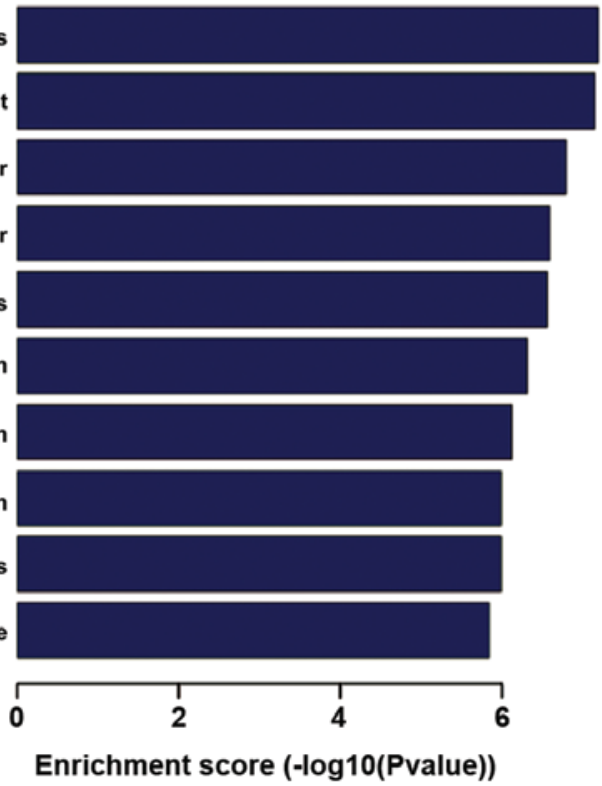

Figure 4. Enriched GO terms of biological processes, molecular functions and cellular components in predicted miRNA targets. Significantly enriched GO terms of target genes regulated by (A) increased and (B) decreased expression of miRNAs in the PAM $_{3}$ CSK4 group. GO, gene ontology; LPS, lipopolysaccharides; miRNA, microRNA. 
C

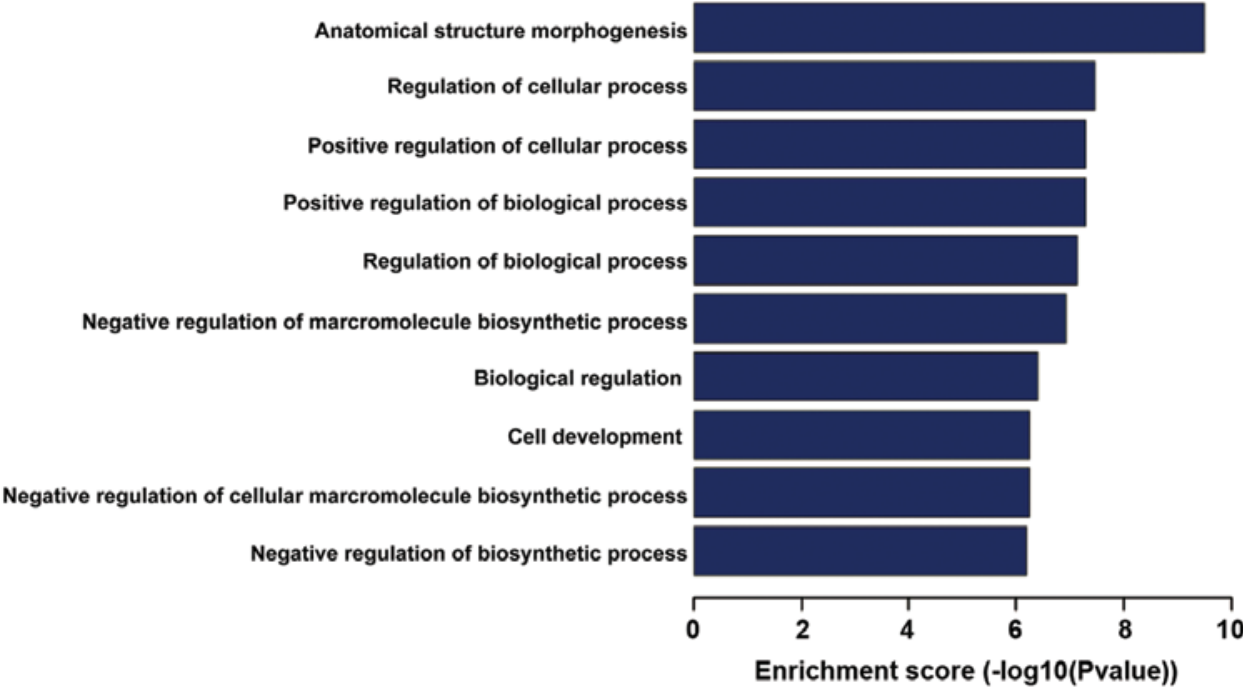

D

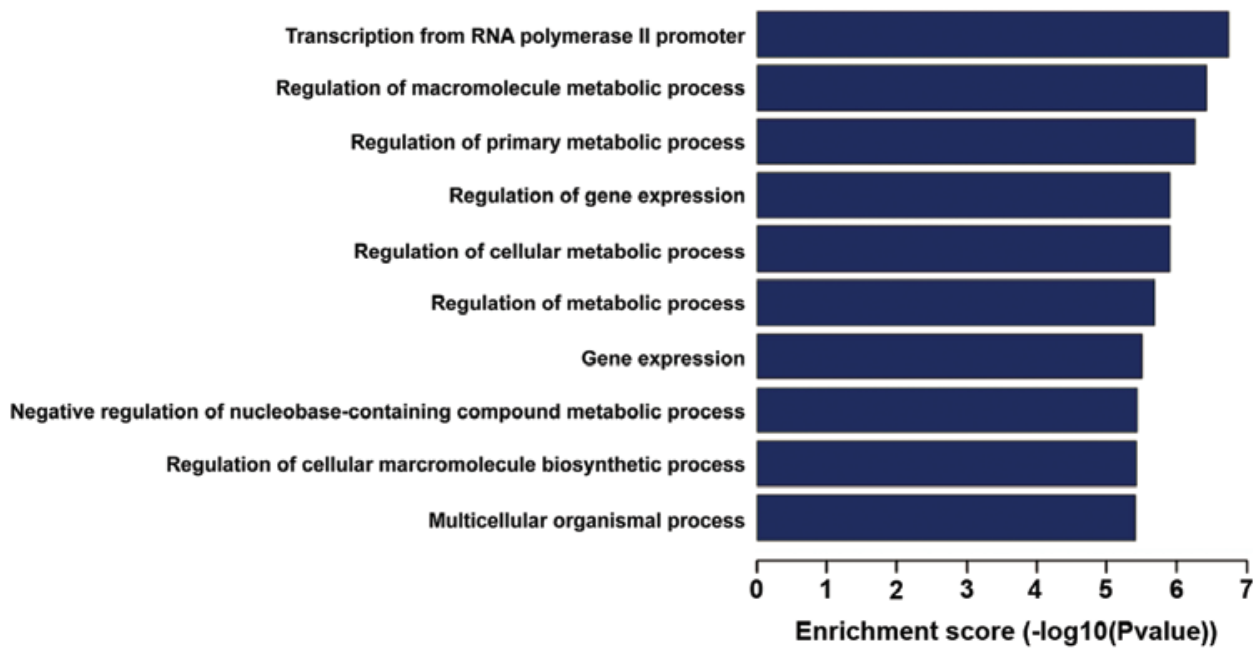

Figure 4. Continued. Enriched GO terms of biological processes, molecular functions and cellular components in predicted miRNA targets. Significantly enriched GO terms of target genes regulated by (C) increased and (D) decreased expression of miRNAs in the lipopolysaccharide group. GO, gene ontology; miRNA, microRNA.

for $10 \mathrm{~min} ; 40$ cycles of $95^{\circ} \mathrm{C}$ for $10 \mathrm{sec}$; and 40 cycles of $60^{\circ} \mathrm{C}$ for $60 \mathrm{sec}$.

\section{Results}

Overview of LPS and PM-induced miRNA expression profiling. To obtain a comprehensive view of the miRNA profile of BM-MSCs stimulated with LPS and PM, Illumine HiSeq 2000 technology was used to detect the global expression level annotated in Sanger miRBase 19.0. A total of 67 miRNAs demonstrated different expression patterns between the LPS and control groups (BM-MSCs without stimulation), with 32 downregulated miRNAs (Table I)and 35 upregulated miRNAs (Table II). In PM-treated cells, the downregulation (Table III) and upregulation (Table IV) were observed for 51 and 46 miRNAs, respectively. To assess the sequencing quality, the length distribution of the clean reads was summarized. Few differences were observed in the length distribution of the sequences from the control and trial libraries (Fig. 1). The most abundant sequence reads were 22,
23, 21 and 24 nt in length, which is consistent with the typical small RNA distribution of mammals.

qPCR verification of known miRNAs. For identification of the authenticity of the miRNAs detected by Illumine HiSeq 2000 technology, 40 known miRNAs from Tables I-IV were randomly selected for further validation with additional samples by qPCR. As presented in Fig. 2, the qPCR data were highly consistent with Illumine HiSeq 2000 technology, confirming the reliability of the HiSeq 2000 sequencing data.

Novel miRNA identification. To identify the novel, unannotated miRNAs in human BM-MSCs, the unlabeled reads were analyzed by miRDeep2. The present study focused on six potential novel miRNAs with the most frequent appearance among all the samples and the highest miRDeep2 score. The expression levels of these six miRNAs were further validated by qPCR. Compared with Illumine HiSeq 2000 sequencing, qPCR indicated the same trend of expression levels for the six novel miRNA candidates (Fig. 3). 
A

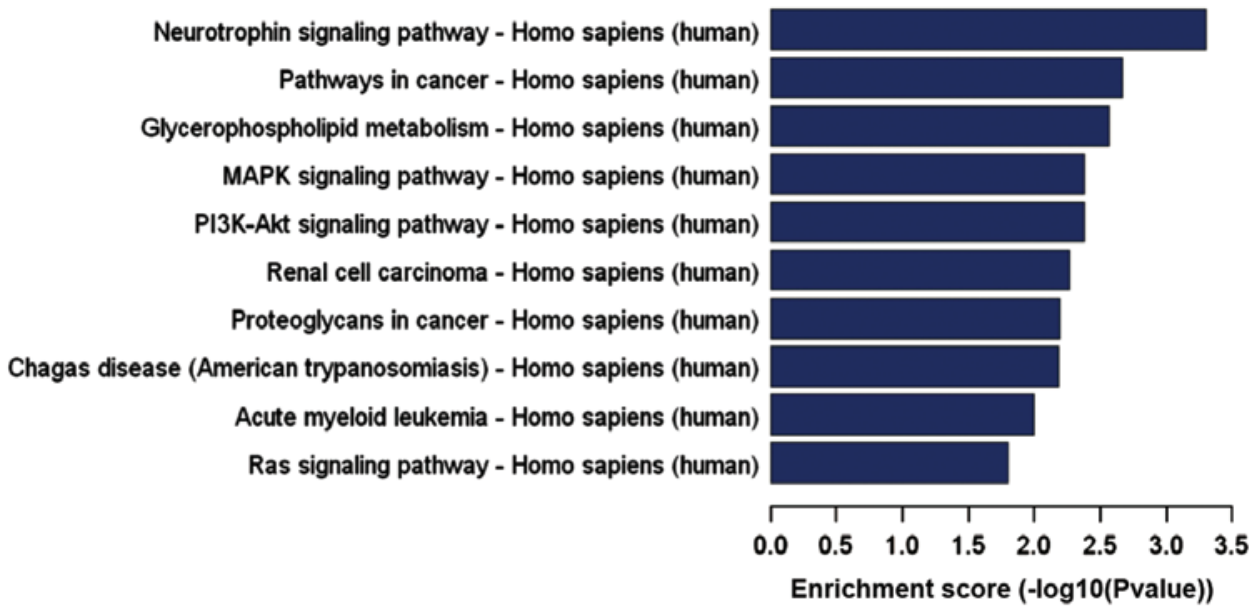

B

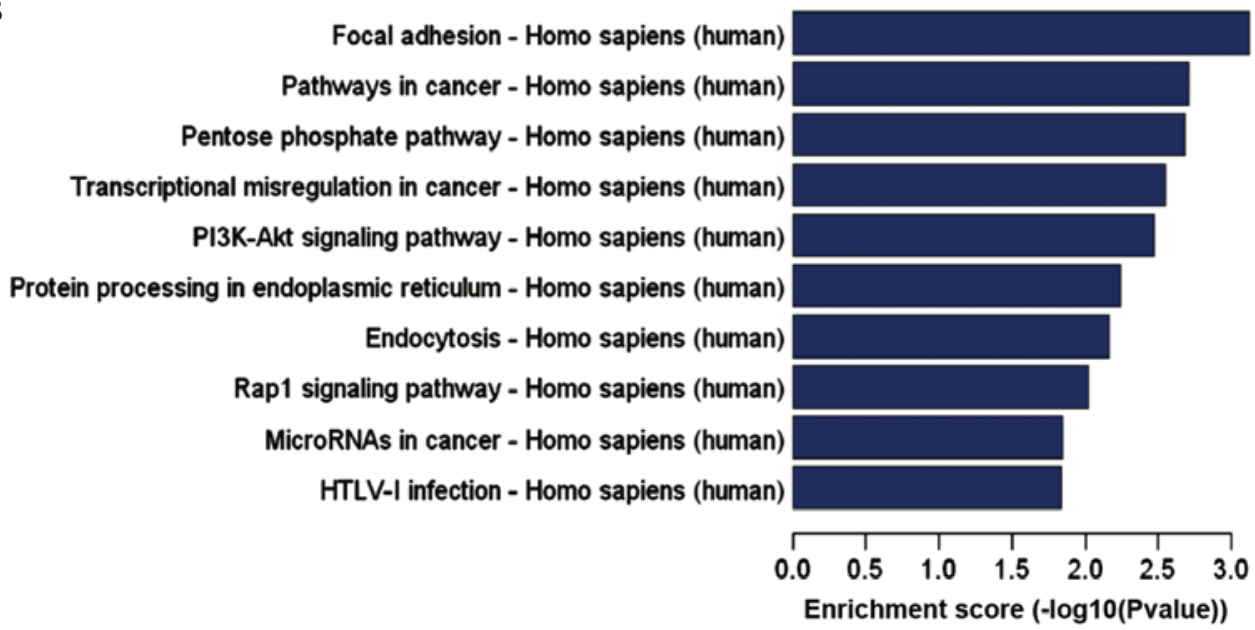

Figure 5. KEGG pathways of target genes demonstrating the greatest enrichment for differentially expressed miRNAs. The KEGG pathways enriched for target genes regulated by (A) increased and (B) decreased expression of miRNAs in the PAM ${ }_{3}$ CSK4 group. KEGG, Kyoto Encyclopedia of Genes and Genomes; miRNA, microRNA; PI3K, phosphatidylinositol-4,5-bisphosphate 3-kinase; MAPK, mitogen-activated protein kinase; mTOR, mammalian target of rapamycin; Rap-1, ras-related protein 1; HTLV, human T-lymphotropic virus; FoxO, forkhead box O.

Predicted target genes of LPS- and PM-responsive miRNAs. To characterize the DE miRNAs between LPS, PM and the controls, the target genes of the DE miRNAs were predicted using three different miRNA target prediction algorithms (TargetScan, MicroCosm and miRanda). Subsequently, the target genes that were identified in all three databases underwent GO analysis. In the LPS group, the targets genes of downregulated miRNAs were significantly enriched in transcripts from the RNA polymerase II promoter and included regulation of macromolecule metabolic processes, gene expression and nucleobase-containing compound metabolic processes; the most enriched GO terms of targets genes of upregulated miRNAs included anatomical structure morphogenesis, regulation of cellular processes, biological processes and cell development. In the PM group, significantly enriched GO terms of targets genes of downregulated miRNAs included regulation of biological process, system development, transcription from RNA polymerase II promoter and cell differentiation; the most enriched GO terms of targets genes of downregulated miRNAs included regulation of signal transduction, cellular process, cell communication and biological process (Fig. 4). KEGG pathway analysis indicated that the predicted target genes were significantly enriched in a wide range of pathways. LPS-regulated miRNAs predominantly target mitogen activated protein kinases (MAPKs), estrogen, T cell receptors, phosphatidylinositol-4,5-bisphosphate 3-kinase (PI3)-Akt, the mammalian target of rapamycin signaling pathway and cancer-associated signaling pathways, while PM-regulated miRNAs target the P13-Akt, ras-related protein 1, neurotrophin, MAPK and Ras signaling pathways (Fig. 5).

\section{Discussion}

A number of studies have reported the expression of TLRs upon MSC and TLR activation in MSCs regulates their functions in immunomodulation, migration, repair and regeneration of damaged tissues/organs (19-24). In addition, a previous study reported that TLR2 agonists (PM) and/or TLR4 agonists (LPS) were able to activate MSCs, thus modulating their hematopoiesis-supporting role in vitro (10). The present study hypothesized that the miRNAs induced by TLR activation may control MSC processes, including immunomodulation, migration, and repair and regeneration of damaged tissues/organs. The present study analyzed the differential miRNA expression profiles in the MSCs derived from 


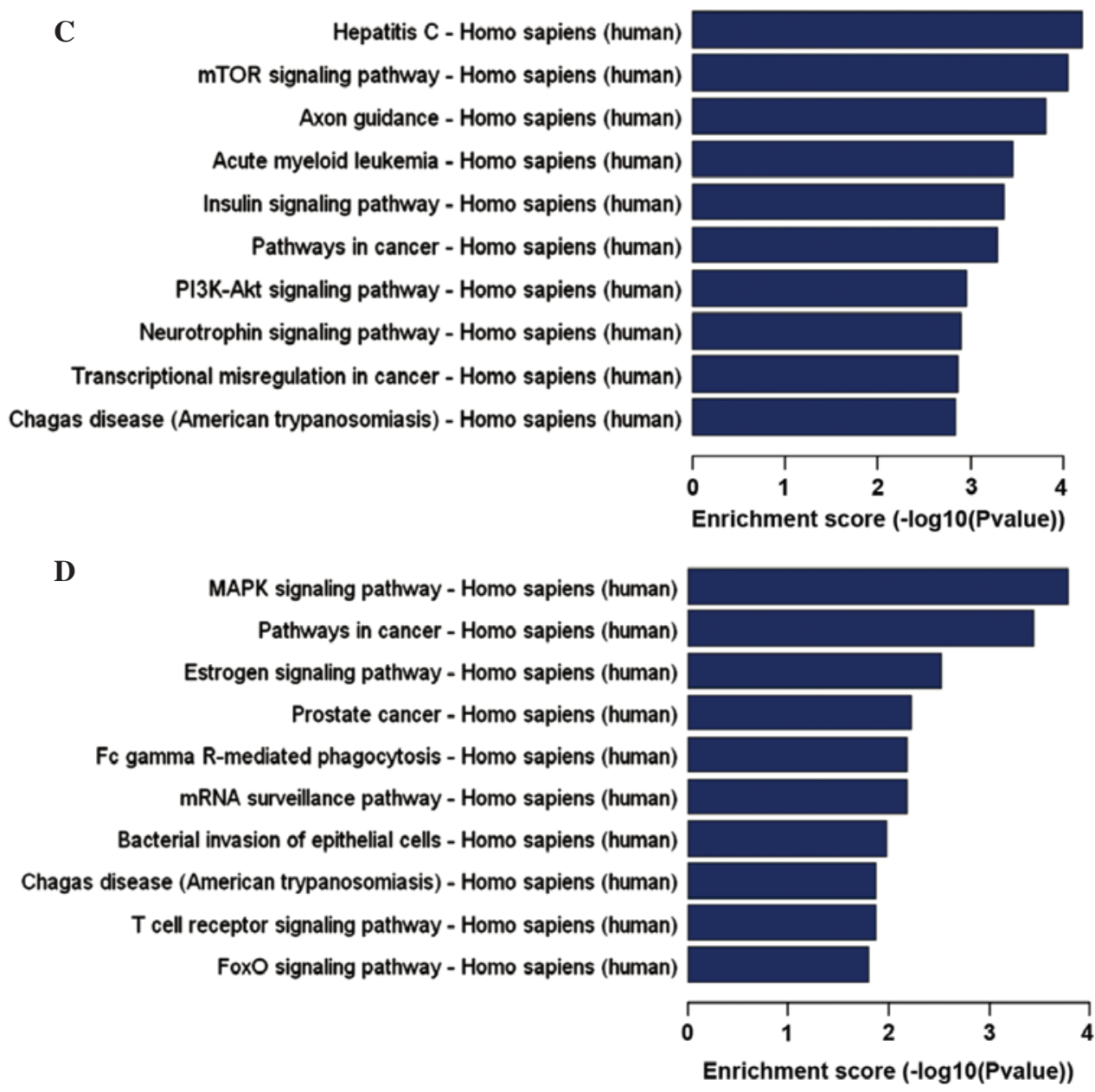

Figure 5. Continued. KEGG pathways of target genes demonstrating the greatest enrichment for differentially expressed miRNAs. The KEGG pathways enriched for target genes regulated by (C) increased and (D) decreased expression of miRNAs in the lipopolysaccharide group. KEGG, Kyoto Encyclopedia of Genes and Genomes; miRNA, microRNA; PI3K, phosphatidylinositol-4,5-bisphosphate 3-kinase; MAPK, mitogen-activated protein kinase; mTOR, mammalian target of rapamycin; Rap-1, ras-related protein 1; HTLV, human T-lymphotropic virus; FoxO, forkhead box O.

human fresh bone marrow and stimulated with LPS or PM. By high-throughput sequencing, compared with the expression levels in unstimulated MSCs, 67 miRNAs were identified with 35 miRNAs upregulated and 32 downregulated following LPS stimulation; 97 miRNAs with 46 miRNAs upregulated and 51 downregulated following PM stimulation. Data from the present study demonstrated that the responses to LPS or PM prompted quick and specific in vitro alterations to the miRNA expression profile of BM-MSCs.

miR-425, which has been demonstrated to be DE and the most markedly downregulated, was observed in the LPS and PM-stimulated BM-MSCs. It was reported that upregulated expression of miR-425 was associated with a variety of types of cancer, including renal and gastric cancers $(25,26)$. A recent study demonstrated that nuclear factor $-\kappa \mathrm{B}(\mathrm{NF}-\kappa \mathrm{B})$-dependent miR-425 upregulation promotes gastric cancer cell growth by targeting phosphatase and tensin homolog in response to IL-1 $\beta$ treatment $(25,26)$. Furthermore, this indicates that the action of miR-425 may mediate cell proliferation. However, to the best of our knowledge, there are no reports investigating the effects of miR-425 in BM-MSCs. Compared with previous studies, the marked difference in expression level of miR-425 indicates that miRNAs may respond differently in LPS or
PM-stimulated BM-MSCs and exert different effects in the different groups.

In accordance with the miRNA results demonstrating upregulation of miR-199a in human BM-MSCs during osteoblastic differentiation and chondrogenesis (27), the most abundantly expressed miRNA in LPS-stimulated BM-MSCs was miR-199a, which was also upregulated in LPS-stimulated leukocytes derived from cord blood (CB) (28). Laine et al (27) demonstrated that cells transfected with pre-miR-199a reduced the proliferation of human MSCs and miR-199a restricts chondrogenic differentiation by suppressing the expression of SRY-box 9, which is a positive regulator of chondrogenesis (29). In addition, miR-199a has been identified as a negative regulator of chondrogenesis (30). Wu et al (31) inferred that the overexpression of miR-199a-5p inhibits the proliferation of keloid fibroblasts. However, Shi et al (32) demonstrated that overexpression of miR-199a-5p promoted the proliferation of porcine preadipocytes and suppressed adipogenic differentiation. These findings indicate that increased expression of miR-199a in LPS-stimulated BM-MSCs may be a key regulator for MSC differentiation and proliferation. As miR-199 was observed to exert opposing effects on proliferation in different cells, 
this is likely explained by miRNA-mRNA targeting, and the different interactions among tissue and cell types and physiological/pathological conditions (33). Further studies are required to investigate the exact underlying mechanism of miR-199a action in BM-MSCs.

The miRNA that was most abundantly expressed in human PM-stimulated BM-MSCs was miR-214. Previous studies reported that miR-214 may be important in promoting myoblast proliferation and differentiation (34); overexpression of miR-214 was connected to gastric cancer tissue, and deletion of miR-214 inhibited the proliferation, migration and invasion of gastric cancer cells (35). The results are consistent with recent findings by Zhang et al (36), that miR-214 is overexpressed in nasopharyngeal carcinoma tissues and cell lines, and that knockdown of miR-214 suppressed cell proliferation and induced apoptosis. However, Derfoul et al (37), demonstrated that overexpression of miR-214 inhibited the proliferation and invasion of breast cancer cells. Thus, the abnormal expression of miR-214 may be closely associated with certain types of cancer by affecting cell growth, differentiation and migration.

However, whether the TLR signaling pathway is regulated by the above-mentioned miRNAs, which are expressed most differentially, and whether their target genes are involved in TLR signal transduction, requires further investigation.

To investigate the function of the LPS- or PM-induced DE miRNAs further, the target genes were predicted, and GO and KEGG pathway analyses were applied to these predicted target genes. The GO term annotation suggests that the presumed target genes of these DE miRNAs in BM-MSCs are involved in a broad range of physiological processes in response to stimuli. Consistent with the GO assay, among those pathways, the MAPK and PI3-Akt signaling pathway are notable, as they have been reported to be important in promoting cell proliferation, growth and differentiation (38).

Notably, in the present study, a number of the verified TLR signaling pathway-associated miRNAs were markedly DE between the control and trial groups. For example, in the TLR4 agonist group, the associated markedly DE miRNAs were miR-146a, miR-155, miR-132, miR-29, miR-199a-5p, let-7b, miR-24,miR-221, miR-181, miR-106a/b, miR-20a, miR-26a and miR-34a (14,15,39-48). In the TLR2 agonist group, the associated markedly DE miRNAs were miR-146a/b, miR-155, miR-132, miR-29, miR-199a-3p, let-7b, miR-24, miR-221, miR-181, miR-106b, miR-92a, miR-210, miR-27b, miR-21, miR-125b, miR-101 and miR-148a/b (12,15,16,38-45,49-54). These miRNAs in BM-MSCs may suggest a potentially important role in TLR signaling regulation. Furthermore, miR-146b was observed to be upregulated in CB leukocytes following LPS stimulation and may control LPS-stimulated neonatal early phases of inflammation via negative feedback loops (28). Ma et al (55) reported that miR-301a was upregulated in umbilical cord-MSCs stimulated with LPS, while miR-301a was not regulated by LPS and PM in the dataset produced in the present study, this notable difference is likely due to the different experimental methods and sources of material.

TLR activation triggers myeloid differentiation primary response gene 88-dependent and -independent downstream signaling cascades, leading to the activation of a number of transcription factors and genes (56-61). These downstream signaling molecules predominantly include transforming growth factor- $\beta$-activated kinase, IL-1R-associated kinases, MAPKs, NF- $\mathrm{KB}$ and tumor necrosis factor-receptor-associated factor 6 (59). It has been demonstrated that following stimulation with ligands specific to TLRs, the NF- $\mathrm{BB}, \mathrm{MAPK}$, and PI3K signaling pathways were activated with a subsequent induction of multiple genes and cytokines (62). Furthermore, combined with KEGG pathways analysis, the results of the present study indicate a critical role for miRNAs, via the TLR signaling pathway, in the growth, differentiation, and migration of LPS and PM-induced BM-MSCs.

During comparison of these two sets of experiments, a number of the TLR signaling pathway-associated miRNAs (miR-146a, miR-155, let-7b, miR-106b, miR-132, miR-29, miR-221 and miR-181) were found to be the same, and the up- or downregulation of specific miRNAs was also consistent, suggesting that LPS- or PM-induced miRNAs may have common targets and exert similar effects in BM-MSCs. Future studies are required to validate these predictions.

Six novel miRNAs that demonstrated marked changes in response to TLR activation were observed in the present study, which were not similar to any known miRNAs. Future investigations are required to predict and functionally validate these DE miRNA targets.

In conclusion, the results of the current study identify the global expression change of miRNAs in BM-MSCs stimulated with LPS and PM, providing a framework for further analysis of miRNAs and their role in mediating TLR signals to regulate the functions of BM-MSCs.

\section{Acknowledgements}

The authors would like to thank Dr Jun Liu for reviewing the manuscript. The present study was supported by the National Natural Science Foundation (grant no. 81270573) and the Natural Science Foundation of Anhui Higher Education Institutions (grant no. KJ2012Z188).

\section{References}

1. Yates LA, Norbury CJ and Gilbert RJ: The long and short of microRNA. Cell 153: 516-519, 2013.

2. Bartel DP: MicroRNAs: Target recognition and regulatory functions. Cell 136: 215-233, 2009

3. Fabian MR, Sonenberg N and Filipowicz W: Regulation of mRNA translation and stability by microRNAs. Annu Rev Biochem 79: 351-379, 2010.

4. Pittenger MF, Mackay AM, Beck SC, Jaiswal RK, Douglas R, Mosca JD, Moorman MA, Simonetti DW, Craig S and Marshak DR: Multilineage potential of adult human mesenchymal stem cells. Science 284: 143-147, 1999.

5. Jiang Y, Jahagirdar BN, Reinhardt RL, Schwartz RE, Keene CD, Ortiz-Gonzalez XR, Reyes M, Lenvik T, Lund T, Blackstad M, et al: Pluripotency of mesenchymal stem cells derived from adult marrow. Nature 418: 41-49, 2002.

6. Charbord P: Bone marrow mesenchymal stem cells: Historical overview and concepts. Hum Gene Ther 21: 1045-1056, 2010

7. Oreffo RO, Cooper C, Mason C and Clements M: Mesenchymal stem cells: Lineage, plasticity and skeletal therapeutic potential. Stem Cell Rev 1: 169-178, 2005.

8. Hwa Cho H, Bae YC and Jung JS: Role of toll-like receptors on human adipose-derived stromal cells. Stem Cells 24: 2744-2752, 2006.

9. van den Berk LC, Jansen BJ, Siebers-Vermeulen KG, Netea MG, Latuhihin T, Bergevoet S, Raymakers RA, Kögler G, Figdor CC, Adema GJ and Torensma R: Toll-like receptor triggering in cord blood mesenchymal stem cells. J Cell Mol Med 13: 3415-3426, 2009. 
10. Wang X, Cheng Q, Li L, Wang J, Xia L, Xu X and Sun Z: Toll-like receptors 2 and 4 mediate the capacity of mesenchymal stromal cells to support the proliferation and differentiation of CD34+cells. Exp Cell Re 318: 196-206, 2012.

11. Benakanakere MR, Li Q, Eskan MA, Singh AV, Zhao J, Galicia JC, Stathopoulou P, Knudsen TB and Kinane DF: Modulation of TLR2 protein expression by miR-105 in human oral keratinocytes. J Biol Chem 284: 23107-23115, 2009.

12. Quinn EM, Wang JH, O'Callaghan G and Redmond HP: MicroRNA-146a is upregulated by and negatively regulates TLR2 signaling. PLoS One 8: e62232, 2013.

13. O'Hara SP, Splinter PL, Gajdos GB, Trussoni CE, Fernandez-Zapico ME, Chen XM and LaRusso NF: NFkappaB p50-CCAAT/enhancer-binding protein beta(C/EBPbeta)-mediated transcriptional repression of microRNA let-7i following microbial infection. J Biol Chem 285: 216-225, 2010.

14. Yang K, He YS, Wang XQ, Lu L, Chen QJ, Liu J, Sun Z and Shen WF: MiR-146a inhibits oxidized low-density lipoprotein-induced lipid accumulation and inflammatory response via targeting toll-like receptor 4. FEBS Lett 585: 854-860, 2011

15. Tili E, Michaille JJ, Cimino A, Costinean S, Dumitru CD, Adair B, Fabbri M, Alder H, Liu CG, Calin GA and Croce CM: Modulation of miR-155 and miR-125b levels following lipopolysaccharide/TNF-alpha stimulation and their possible roles in regulating the response to endotoxin shock. J Immunol 179: 5082-5089, 2007.

16. Curtale G, Mirolo M, Renzi TA, Rossato M, Bazzoni F and Locati M: Negative regulation of Toll-like receptor 4 signaling by IL-10-dependent microRNA-146b. Proc Natl Acad Sci USA 110 11499-11504, 2013.

17. Ceppi M, Pereira PM, Dunand-Sauthier I, Barras E, Reith W, Santos MA and Pierre P: MicroRNA-155 modulates the interleukin-1 signaling pathway in activated human monocyte-derived dendritic cells. Proc Natl Acad Sci USA 106: 2735-2740, 2009.

18. Livak KJ and Schmittgen TD: Analysis of relative gene expression data using real-time quantitative PCR and the 2(-Delta Delta C(T)) Method. Methods 25: 402-408, 2001

19. Hwa Cho H, Bae YC and Jung JS: Role of toll-like receptors on human adipose-derived cells. Stem Cells 24: 2744-2752, 2006

20. Pevsner-Fischer M, Morad V, Cohen-Sfady M, Rousso-Noori L, Zanin-Zhorov A, Cohen S, Cohen IR and Zipori D: Toll-like receptors and their ligands control mesenchymal stem cell functions. Blood 109: 1422-1432, 2007.

21. Liotta F, Angeli R, Cosmi L, Filì L, Manuelli C, Frosali F, Mazzinghi B, Maggi L, Pasini A, Lisi V, et al: Toll-like receptors 3 and 4 are expressed by human bone marrow-derived mesenchymal stem cells and can inhibit their T cell modulatory activity by 634 impairing Notch signaling. Stem Cells 26 : 279-289, 2008

22. Opitz CA, Litzenburger UM, Lutz C, Lanz TV, Tritschler I, Köppel A, Tolosa E, Hoberg M, Anderl J, Aicher WK, et al: Toll-like receptor engagement enhances the immunosuppressive properties of human bone marrow-derived mesenchymal stem cells by inducing indoleamine-2,3-dioxygenase-1 via interferon-beta and protein kinase R. Stem Cells 27: 909-919, 2009.

23. Tomchuck SL, Zwezdaryk KJ, Coffelt SB, Waterman RS, Danka ES and Scandurro AB: Toll-like receptors on human mesenchymal stem cells drive their migration and immunomodulating responses. Stem Cells 26: 99-107, 2008

24. Romieu-Mourez R, François M, Boivin MN, Bouchentouf M, Spaner DE and Galipeau J: Cytokine modulation of TLR expression and activation in mesenchymal stromal cells leads to a proinflammatory phenotype. J Immunol 182: 7963-7973, 2009

25. White NM, Bao TT, Grigull J, Youssef YM, Girgis A, Diamandis M, Fatoohi E, Metias M, Honey RJ, Stewart R, et al: miRNA profiling for clear cell renal cell carcinoma: Biomarker discovery and identification of potential controls and consequences of miRNA dysregulation. J Urol 186: 1077-1083, 2011.

26. Ma J, Liu J, Wang Z, Gu X, Fan Y, Zhang W, Xu L, Zhang J and Cai D: NF-kappaB-dependent MicroRNA-425 upregulation promotes gastric cancer cell growth by targeting PTEN upon IL-1 $\beta$ induction. Mol Cancer 13: 40, 2014.

27. Laine SK, Alm JJ, Virtanen SP, Aro HT and Laitala-Leinonen TK MicroRNAs miR-96, miR-124 and miR-199a regulate gene expression in human bone marrow-derived mesenchymal stem cells. J Cell Biochem 113: 2687-2695, 2012

28. Chen J, Liu Z and Yang Y: In vitro screening of LPS-induced miRNAs in leukocytes derived from cord blood and their possible roles in regulating TLR signals. Pediatr Res 75: 595-602, 2014.
29. Akiyama H: Control of chondrogenesis by the transcription factor Sox9. Mod Rheumatol 18: 213-219, 2008

30. Lin EA, Kong L, Bai XH, Luan Y and Liu CJ: miR-199a, a bone morphogenic protein 2-responsive MicroRNA, regulates chondrogenesis via direct targeting to Smad1. J Biol Chem 284: $11326-11335,2009$.

31. Wu ZY, Lu L, Liang J, Guo XR, Zhang PH and Luo SJ: Keloid microRNA expression analysis and the influence of miR-199a-5p on the proliferation of keloid fibroblasts. Genet Mol Res 13: 2727-2738, 2014.

32. Shi XE, Li YF, Jia L, Ji HL, Song ZY, Cheng J, Wu GF, Song CC, Zhang QL, Zhu JY and Yang GS: MicroRNA-199a-5p affects porcine preadipocyte proliferation and differentiation. Int J Mol Sci 15: 8526-8538, 2014

33. Krek A, Grün D, Poy MN, Wolf R, Rosenberg L, Epstein EJ, MacMenamin P, da Piedade I, Gunsalus KC, Stoffel M and Rajewsky N: Combinatorial microRNA target predictions. Nat Genet 37: 495-500, 2005.

34. Feng Y, Cao JH, Li XY and Zhao SH: Inhibition of miR-214 expression represses proliferation and differentiation of $\mathrm{C} 2 \mathrm{C} 12$ myoblasts. Cell Biochem Funct 29: 378-383, 2011.

35. Yang TS, Yang XH, Wang XD, Wang YL, Zhou B and Song ZS: MiR-214 regulate gastric cancer cell proliferation, migration and invasion by targeting PTEN. Cancer Cell Int 13: 68, 2013.

36. Zhang ZC, Li YY, Wang HY, Fu S, Wang XP, Zeng MS, Zeng YX and Shao JY: Knockdown of miR-214 promotes apoptosis and inhibits cell proliferation in nasopharyngeal carcinoma. PLoS One 9: e86149, 2014

37. Derfoul A, Juan AH, Difilippantonio MJ, Palanisamy N, Ried T and Sartorelli V: Decreased microRNA-214 levels in breast cancer cells coincides with increased cell proliferation, invasion and accumulation of the Polycomb Ezh2 methyltransferase. Carcinogenesis 32: 1607-1614, 2011.

38. Brzezianska E and Pastuszak-Lewandoska D: A minireview: The role of MAPK/ERK and PI3K/Akt pathways in thyroid follicular cell-derived neoplasm. Front Biosci (Landmark Ed) 16: 422-439, 2011.

39. Nahid MA, Yao B, Dominguez-Gutierrez PR, Kesavalu L, Satoh M and Chan EK: Regulation of TLR2-mediated tolerance and cross-tolerance through IRAK4 modulation by miR-132 and miR-212. J Immunol 190: 1250-1263, 2013.

40. Ahmed F, Shiraishi T, Vessella RL and Kulkarni P: Tumor necrosis factor receptor associated factor-4: An adapter protein overexpressed in metastatic prostate cancer is regulated by microRNA-29a. Oncol Rep 30: 2963-2968, 2013.

41. Chen R, Alvero AB, Silasi DA, Kelly MG, Fest S, Visintin I, Leiser A, Schwartz PE, Rutherford T and Mor G: Regulation of IKKB by miR-199a affects NF-kappB activity in ovarian cancer cells. Oncogene 27: 4712-4723, 2008.

42. Zhou R, O'Hara SP and Chen XM: MicroRNA regulation of innate immune responsesin epithelial cells. Cell Mol Immunol 8: 371-379, 2011

43. Huang Z, Chen X, Yu B and Chen D: Cloning and functional characterization of rat stimulator of interferon genes (STING) regulated by miR-24. Dev Comp Immunol 37: 414-420, 2012

44. Lai NS, Yu HC, Chen HC, Yu CL, Huang HB and Lu MC: Aberrant expression of microRNAs in T cells from patients with ankylosing spondylitis contributes to the immunopathogenesis. Clin Exp Immunol 173: 47-57, 2013

45. Zhao J, Gong AY, Zhou R, Liu J, Eischeid AN and Chen XM: Downregulation of PCAF by miR-181a/b provides feedback regulation to TNF- $\alpha$-induced transcription of proinflammatory genes in liver epithelial cells. J Immunol 188: 1266-1274, 2012.

46. Sharma A, Kumar M, Aich J, Hariharan M, Brahmachari SK, Agrawal A and Ghosh B: Posttranscriptional regulation of interleukin-10 expression by hsa-miR-106a. Proc Natl Acad Sci USA 106: 5761-5766, 2009.

47. Zhang M, Liu Q, Mi S, Liang X, Zhang Z, Su X, Liu J, Chen Y, Wang M, Zhang Y, et al: Both miR-17-5p and miR-20a alleviate suppressive potential of myeloid-derived suppressor cells by modulating STAT3 expression. J Immunol 186: 4716-4724, 2011

48. Witwer KW, Sisk JM, Gama L and Clements JE: MicroRNA regulation of IFN-beta protein expression: Rapid and sensitive modulation of the innate immune response. J Immunol 184: 2369-2376, 2010.

49. Lai L, Song Y, Liu Y, Chen Q, Han Q, Chen W, Pan T, Zhang Y, Cao X and Wang Q: MicroRNA-92a negatively regulates Toll-like receptor (TLR)-triggered inflammatory response in macrophages by targeting MKK4 kinase. J Biol Chem 288: 7956-7967, 2013 . 
50. Qi J, Qiao Y, Wang P, Li S, Zhao W and Gao C: MicroRNA-210 negatively regulates LPS-induced production of proinflammatory cytokines by targeting NF- $\mathrm{KB} 1$ in murine macrophages. FEBS Lett 586: 1201-1207, 2012.

51. Jennewein C, von Knethen A, Schmid T and Brüne B: MicroRNA-27b contributes to lipopolysaccharide-mediated peroxisome proliferator-activated receptor gamma (PPARgamma) mRNA destabilization. J Biol Chem 285: 11846-11853, 2010.

52. Lu TX, Munitz A and Rothenberg ME: MicroRNA-21 is up-regulated in allergic airway inflammation and regulates IL-12p35 expression. J Immunol 182: 4994-5002, 2009.

53. Zhu QY, Liu Q, Chen JX, Lan K and Ge BX: MicroRNA-101 targets MAPK phosphatase-1 to regulate the activation of MAPKs in macrophages. J Immunol 185: 7435-7442, 2010.

54. Liu X, Zhan Z, Xu L, Ma F, Li D, Guo Z, Li N and Cao X: MicroRNA-148/152 impair innate response and antigen presentation of TLR-triggered dendritic cells by targeting CaMKII $\alpha$. J Immunol 185: 7244-7251, 2010.

55. Ma F, Chen D, Chi Y, Chen F, Li X and Han Z: The expression and role of miR-301a in human umbilical cord-derived mesenchymal stromal cells. Cytotherapy 15: 1511-1516, 2013.
56. Akira S, Uematsu S and Takeuchi O: Pathogen recognition and innate immunity. Cell 124: 783-801, 2006.

57. Ozinsky A, Underhill DM, Fontenot JD, Hajjar AM, Smith KD, Wilson CB, Schroeder L and Aderem A: The repertoire for pattern recognition of pathogens by the innate immune system is defined by cooperation between toll-like receptors. Proc Natl Acad Sci USA 97: 13766-13771, 2000.

58. Pasare C and Medzhitov R: Toll-like receptors: Linking innate and adaptive immunity. Adv Exp Med Biol 560: 11-18, 2005.

59. Hoebe K, Jiang Z, Georgel P, Tabeta K, Janssen E, Du X and Beutler B: TLR signaling pathways: Opportunities for activation and blockade in pursuit of therapy. Curr Pharm Des 12: 4123-4134, 2006

60. Kawai T and Akira S: TLR signaling. Semin Immunol 19: 24-32, 2007.

61. O'Neill LA and Bowie AG: The family of five: TIR-domain-containing adaptors in Toll-like receptor signalling. Nat Rev Immunol 7: 353-364, 2007.

62. DelaRosa O and Lombardo E: Modulation of adult mesenchymal stem cells activity by toll-like receptors: Implications on therapeutic potential. Mediators Inflamm 2010: 865601, 2010. 